\title{
Study of knowledge and attitude towards breastfeeding in antenatal mothers at Chamarajanagara Institute of Medical Sciences, Chamarajanagar, India
}

\author{
Pradeep Musale Ramachandra1, Nayana Davanagere Hiremath ${ }^{2 *}$
}

\author{
${ }^{1}$ Department of Obstetrics and Gynecology, Chamarajanagara Institute of Medical Sciences, Chamarajanagara \\ Karnataka, India \\ ${ }^{2}$ Department of Obstetrics and Gynecology, Rajarajeshwari Medical College, Bangalore, Karnataka, India
}

Received: 15 April 2019

Revised: 12 May 2019

Accepted: 31 May 2019

\section{*Correspondence:}

Dr. Nayana Davanagere Hiremath,

E-mail: dh.nayana@gmail.com

Copyright: () the author(s), publisher and licensee Medip Academy. This is an open-access article distributed under the terms of the Creative Commons Attribution Non-Commercial License, which permits unrestricted non-commercial use, distribution, and reproduction in any medium, provided the original work is properly cited.

\begin{abstract}
Background: exclusive breast feeding practice is major pillar in preventing infant mortality. This study was undertaken to know the knowledge and attitude of antenatal mothers towards breast feeding.

Methods: this is a cross sectional study in our hospital in which 264 antenatal mothers were included after verbal consent. Antenatal mothers were explained about the study, their knowledge and attitude regarding breast feeding is assessed by questionnaire. Study will be analysed by appropriate statistical analysis.

Results: In total of 264 antenatal mothers, most of them were between 20-25 years, majority in third trimester. Among them $68.2 \%$ knows breast feeding should be initiated within first hour of delivery, $90.2 \%$ is for no prelacteal feeds and $95.8 \%$ wants to feed colostrum. Only $42.4 \%$ wants to continue breastfeeding for two years. About $62.9 \%$ of antenatal mothers wants to supplement the child with food after six months.81.8\% knows breast feeding is not only helpful to the baby but also it prevents breast cancer in mother later in life. $21.2 \%$ wants to feed complimentary feeds as early as 3 months.

Conclusions: our study on knowledge of breast feeding among antenatal mothers shown most of them are against prelacteal feeds and wants to feed colostrums, but initiation of breast feeding within first hour of birth and weaning after six months and continuation of breast milk up to two years is lagging. Multiple educational sessions, visual aids, pamphlets, electronic media, counseling during antenatal period and in early post natal period is necessary to inculcate appropriate knowledge on breast feeding.
\end{abstract}

Keywords: Antenatal mothers, Breast feeding, Knowledge

\section{INTRODUCTION}

Breast milk is the best food for the new born. It has got not only nutritive value but also provides natural passive immunity to protect the new born from the diseases.
A major contribution of infant mortality can be prevented by practicing exclusive breast feeding. Unfortunately in India rate of early initiation of breast feeding is only $24.5 \%$ and the median duration of breast feeding among last-born children is as brief as two months. Further the rate of exclusive breast feeding (EBF) drops 
progressively from $51 \%$ at $2-3$ months of age to $28 \%$ at 4-5 months of age. ${ }^{1}$

A series of systematic reviews shown breast feeding decreases child infections and dental malocclusions and increasing in mental intelligence. Mothers who breastfed are at decreased risk of brest cancer. Improving breastfeeding rates globally can prevent over 800,000 deaths in children under five years and 20,000 breast cancer deaths annually. ${ }^{2}$

WHO recommends initiation of exclusive breast feeding (EBF) within an hour of birth to six months, thereafter complimentary supplementation of food and continue breast feeding to two years and beyond..$^{3-5}$

Several misconceptions in the community hinder the practice of exclusive breast feeding and practices prelacteal feeds immediately after birth. Antenatal period is the best period to educate women regarding advantages of EBF. This study is conducted to know the knowledge and attitude regarding EBF at chamarajanagara instiute of medical sciences, chamaajanagara.and sensitising the antenatal mothers about advantages of EBF.

\section{METHODS}

This is a cross sectional study in our hospital in which 264 antenatal mothers are included from October 2018 to December 2018. Institutional ethical committee approval was taken to conduct this study in the department of obstetrics and gynecology, Chamarajanagara institute of medical sciences (CIMS). Pregnant ladies attending outpatient department in our hospital daily between 9:00am to 11:00am are included in the study.

Study was briefed to pregnant ladies, whosoever willing to participate were given questionnaire (printed both in English and local language) questions were explained to them, time was given to fill the questionnaire. Data was collected, after this Breast feeding practices counseling and video demonstrations were conducted to educate them. Data entered were collected and analyzed by percentage.

\section{Inclusion criteria}

- The all pregnant mothers attending outpatient department given consent to participate in the study.

\section{Exclusion criteria}

- Any woman who is not pregnant attending outpatient department, all post natal women.

\section{RESULTS}

In this study a total of 264 antenatal mothers are included.

Table 1: Age and educational status and gravidity of antenatal mothers.

\begin{tabular}{|llll|}
\hline $\begin{array}{l}\text { Age in } \\
\text { years }\end{array}$ & Frequencies & Variables & Percentage \\
\hline & 20-25 years & 57 & $21.6 \%$ \\
\hline & 26-30 years & 56 & $21.2 \%$ \\
\hline & $>30$ years & 19 & $7.2 \%$ \\
\hline $\begin{array}{l}\text { Education } \\
\text { status }\end{array}$ & Illitrate & Nil & \\
\hline & $1-5^{\text {th }}$ std & 29 & $11 \%$ \\
\hline & $6-10^{\text {th }}$ std & 146 & $55.3 \%$ \\
\hline & $11-12^{\text {th }}$ std & 67 & $25.4 \%$ \\
\hline & $>12^{\text {std }}$ & 22 & $8.3 \%$ \\
\hline Gravida & Primi & 147 & $55.7 \%$ \\
\hline & Multi & 117 & $44.3 \%$ \\
\hline $\begin{array}{l}\text { Gestational } \\
\text { age }\end{array}$ & I trimeser & 18 & $6.8 \%$ \\
\hline & II trimester & 42 & $15.9 \%$ \\
\hline & III trimester & 204 & $77.3 \%$ \\
\hline
\end{tabular}

Table: 2 various breast feeding variables and its percentage.

\begin{tabular}{|llll|}
\hline & Variables & frequency & Percentage \\
\hline First Breast feeding given by mother after delivery & $<1$ hour & 180 & $68.2 \%$ \\
\hline & $1-4$ hours & 77 & $29.2 \%$ \\
\hline & $1-3$ days & 7 & $2.6 \%$ \\
\hline Prelacteal feeds should be given & $>3$ days & Nil & \\
\hline & No & 240 & $90.9 \%$ \\
\hline Feeding Yellow milk after delivery & Yes & 24 & $9.1 \%$ \\
\hline & Yes & 253 & $95.8 \%$ \\
\hline Breast feeding should be continued for & No & 11 & $4.2 \%$ \\
\hline & 6 months only & 83 & $31.4 \%$ \\
\hline & 1 year & 36 & $13.7 \%$ \\
\hline
\end{tabular}


Most common age group involved is between 20-25 years, (50\%). All are literates; most of them are studied up to secondary school (\%55.3\%). Our Study has more of Primigravidas $(55.7 \%)$ and most of the antenatal mothers are in third trimester (Table 1).

Almost $30 \%$ of antenatal mothers don't know the benefits of early breast feeding. $9.1 \%$ of the mothers still inclined towards prelacteal feeds, $31.4 \%$ of the women want to stop the breast feeding at 6 months of age only (Table 2 ).
About $62.9 \%$ of antenatal mothers wants to supplement the child with food after six months.81.8\% knows breast feeding is not only helpful to the baby but also it prevents breast cancer later in life. $21.2 \%$ wants to feed complimentary feeds as early as 3 months.

$21.2 \%$ of antenatal mothers want to wean the infants after three months. $19.2 \%$ of mothers don't know benefits of breast feeding to the mother (Table 3).

Table 3: Assessment of knowledge of breast feeding in antenatal mothers.

\begin{tabular}{|llll|}
\hline & Variables & Frequency & Percentage \\
\hline Breast feeding should be supplemented with other food & At birth & 06 & $2.3 \%$ \\
\hline & After 3 months & 56 & $21.2 \%$ \\
\hline & After 6 months & 166 & $62.9 \%$ \\
\hline Breast feeding prevents breast cancer later in life & After 9 months & 36 & $13.6 \%$ \\
\hline Breast feeding sagging of breast disfigure woman & & 216 & $81.8 \%$ \\
\hline Breast feeding cause No use or harm to mother & & 04 & $1.5 \%$ \\
\hline
\end{tabular}

\section{DISCUSSION}

Breast milk is the best milk for the newborn baby. It is a perfect nutrition, and provides immunity to new born. It protects infant against infectious diseases such as gastroenteritis, respiratory diseases and otits media. And chronic diseases like childhood obesity and asthma. For mother it not only provides bonding but also prevents breast and ovarian cancer. ${ }^{6}$

National family health survey (NFHS) 4 data 2015-16 for 15 states from India showed a rise in institutional deliveries to $82.2 \%$ with intimation of early breastfeeding stagnant at $47.7 \%$ only. ${ }^{7}$ In our study common age group is between 20-25 years and in third trimester (Table 1). 68.2\% of antenatal mothers want to initiate breast feeding within first hour of birth (Table 2). Our study data is little improved compared to other state NFHS data.

In our study $90 \%$ of mothers are against prelacteal feeds (Table 2) compared to only $68 \%$ are against prelacteal feeds in other district of Karnataka. ${ }^{8}$

Mothers intend to Wean infants after 6 months is $62.9 \%$ whereas $21.2 \%$ wants to wean their infants after 3 months in our study. Whereas weaning is $86.5 \%$ after 6 months and $13.5 \%$ after 3 months in Upadhye JV et al. ${ }^{9}$

There is a estimation of 1.4 million deaths and $10 \%$ of the disease burden in less than 5 years of age is found in children with sub optimal breast feeding and exclusive breast feeding less than 6 months of age. ${ }^{10}$
Lumbigaon $\mathrm{P}$ et al, showed that breast feeding education and counseling in antenatal mothers increases both exclusive breast feeding and duration of breast feeding among mothers post natally. ${ }^{11}$

There is a strong evidence that maternal confidence /self efficacy is directly correlated to breast feeding duration and that high women's confidence the more likely she continue breast feeding. ${ }^{12}$

\section{CONCLUSION}

Our study on knowledge of breast feeding among antenatal mothers shown most of them are against prelacteal feeds and wants to feed colostrums, but initiation of breast feeding within first hour of birth and weaning after six months and continuation of breast milk up to two years is lagging. Multiple educational sessions, visual aids, pamplets, electronic media, counseling during antenatal period and in early post natal period is necessary to inculcate appropriate knowledge on breast feeding.

\section{Funding: No funding sources \\ Conflict of interest: None declared}

Ethical approval: The study was approved by the Institutional Ethics Committee

\section{REFERENCES}

1. Tiwari S, Bharadva K, Yadav B, Malik S, Gangal P, Banapurmath $\mathrm{CR}$, et al. Infant and young child feeding guidelines 2016, for the IYCF chapter of IAP 2016;53:703. 
2. Guideline protecting, promoting and supporting breastfeeding in facilities is providing maternity and new born services. World health organization. 2017:15. Available at; https;//apps.who.int $>9789241$ 550086-eng.pdf.

3. Global strategy for infant and young child feeding, world health organization, Geneva. 2003:7-8. Available at; whqlibdoc. who.int $>$ publications $>2003$ >9241562218.pdf.

4. Resolution WHA 65.6. Comphrensive implementation plan on maternal infant and young child nutrition in; sixty-fifth world health assemblies Geneva 21-26 may 2012. Resolutions and decisions annexues Geneva. World health organization's. 2012:12-13.

5. The global strategy for womens childerns and adolescents health (2016-2030) survive, thrive, transform. GENEVA; everywoman every child; 2015. Available at: https;//Globalstrategy.every womaneverychild.org,gyreport_200915_FINAL_WE B.pdf.

6. Balogun OO, Sullivan EJ, Fadden A, Ota E, Gavine A, Garner CD, et al. Interventions for promoting the initiations of breastfeeding, cochrane database syst Rev. 2016(11);6:CD001688.

7. Sharma S, Sharma C, Kumar A. Improving the breast feeding practises in Healthy Neonates During Hospital stay using Quality improvement methodology; Indian paediatrics. 2018;55:757.
8. Jayarama S, Ramaiah R. Prelacteal feeding practice among mothers in rural area of Karnataka; a cross sectional study. Int J Comm Med Pub Health. 2017;4(8):2919-23.

9. Upadhye JV, Mandalik MR, Upadhye AJ, Marathe SM, Matte AR, Upadhye JJ. Knowledge, attitudes and breast feeding practices of postnatal mothers in central India. Int $\mathbf{J}$ Reprod Conracept Obstet Gynecol. 2018;7(9):3546-50.

10. Ekambarum M, Bhat V, Ahmed MA. Knowledge attitude and practice of breast feeding among post natal mothers. Current Paediatrics Res. 2010:14(2).

11. Lumbigaon P, Maris R, Laopaiboom M, Festin MR, Ho JJ, Hakmi M. Antenatal breast feeding education for in creasine in breast feeding duration. The cochrane database of systemic reviews. 2011;11:006425

12. Noel-Weiss J, Basset V, Cragg B. Developing a prenatal breast feeding workshop to support maternal breast feeding self-efficacy. J Obst Gynecol Neonat Nursing. 2006;35(3):349-57.

Cite this article as: Ramachandra PM, Hiremath ND. Study of knowledge and attitude towards breastfeeding in antenatal mothers at Chamarajanagara Institute of Medical Sciences, Chamarajanagar, India. Int J Reprod Contracept Obstet Gynecol 2019;8:2687-90. 